\title{
Оптическая нейронная сеть на основе синтетических фотонных решеток
}

\author{
А.В. Паньков ${ }^{1}, \underline{\text { И.Д. Ватник }}{ }^{1, *}$, Д.В. Чуркин ${ }^{1}$, А.А. Сухоруков ${ }^{2}$ \\ ${ }^{1}$ Новосибирский государственный университет \\ ${ }^{2}$ Nonlinear Physics Centre, Research School of Physics, Australian National University, Canberra, ACT \\ 2601, Australia \\ *E-mail: i.vatnik@nsu.ru
}

DOI: 10.31868/RFL2020.130-131

Область нейронных сетей развивается крайне быстро. Одновременно растут как сложность архитектуры нейронных сетей, так и сложность решаемых с их помощью задач. В цифровых нейронных сетях (ЦНН) при увеличении размера самой сети число требуемых для ее работы математических операций растет нелинейно, что приводит к нелинейному росту времени, требуемому для выполнения поставленной задачи. Оптические же нейронные сети (OHH) обладают большим потенциалом, т.к. обработка информации в таких системах физически реализована на основе пространственного распределения излучения $[1,2]$ и по скорости ограничена буквально скоростью света, в то время как в ЦНН скорость ограничена скоростью работы процессоров. По этой причине актуальной задачей является разработка и реализация ОНН, основанных на различных подходах

В данной работе нами рассмотрена возможность использования в качестве ОНН оптоволоконную систему, известную как «синтетическая фотонная решетка» (СФР) [3]. СФР состоит из двух оптоволоконных петель различной длины с контролируемыми набегами фаз в каждой, соединенных между собой настраиваемым оптоволоконным делителем (Рис.1а). Гибкость в управлении световыми импульсами в такой системе позволила продемонстрировать в ней множество различных физических эффектов [4-7].

Эволюция оптических импульсов, распространяющихся в СФР, аналогична эволюции сигналов, распространяющихся по синапсам между нейронами. При этом, однако, каждый из слоев в СФР реализуется при одном обходе светом волоконной петли, а каждый узел («нейрон») в слое имеет связи только с двумя узлами в следующем слое (рис. 16 и 1в). Важно отметить, что в отличие от других оптических нейронных сетей, эволюция света в СФР происходит во времени, а не в пространстве.

Мы разработали алгоритм обучения нейронной сети, реализованной в СФР, на основе классического метода обратного распространения ошибки с учетом особенностей распространения оптического сигнала в СФР. Если обычно в процессе обучения корректируются независимо веса синапсов, то в данном алгоритме корректировке подвергаются такие параметры как фазовые сдвиги на короткой и длиной петле $(\varphi, \psi)$ и коэффициент оптоволоконного делителя, вставленного между петлями. При этом каждый из этих параметров изменяет несколько весов связей между нейронами одновременно. 

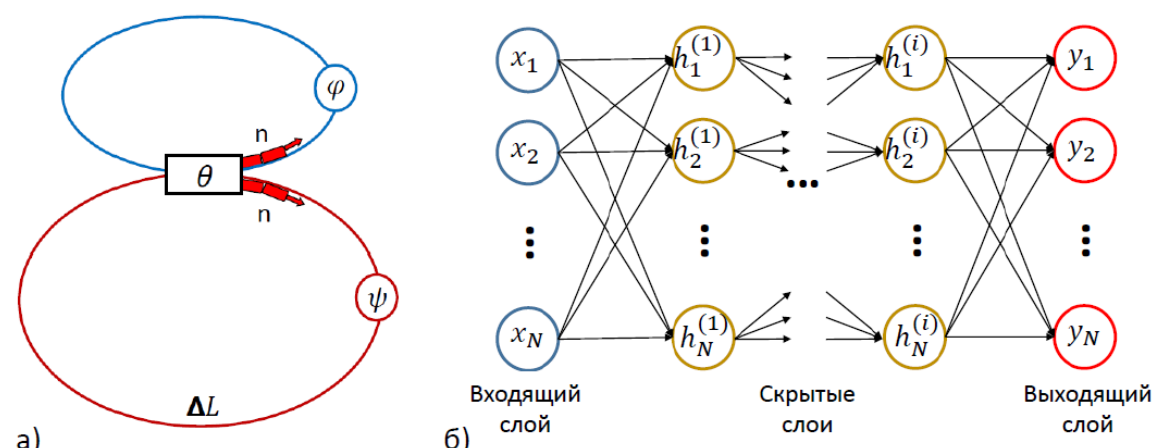

a)

б)
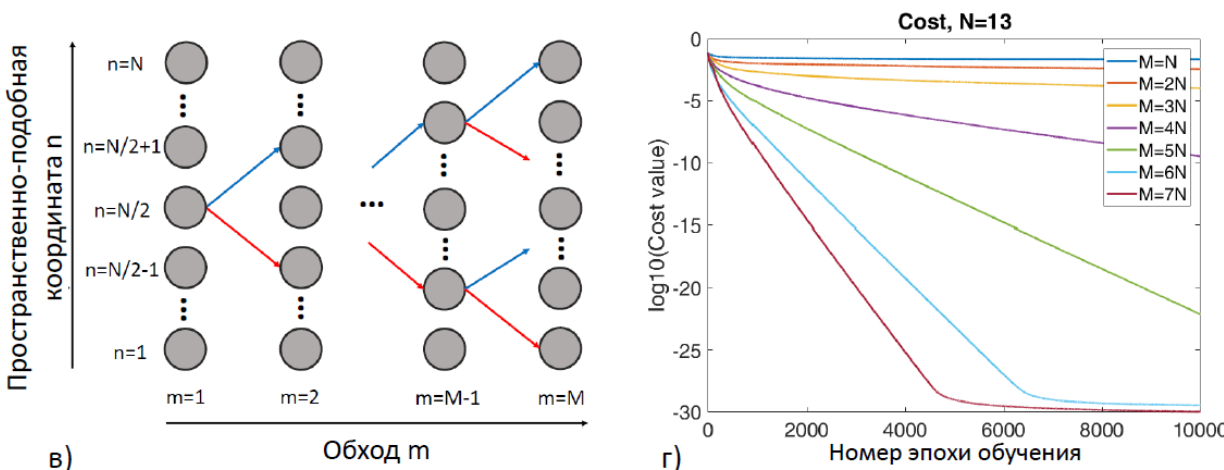

Рис. 1. а) Синтетическая фотонная решетка б) Классическая полностью соединенная нейронная сеть в) Схематическое представление СФР в виде нейронной сети с ограниченным количеством связей между нейронами г) Зависимость функции ошибки (cost value) при обучении ОНН на основе СФР при различных размерах СФР.

В качестве тестовой решалась задача поиска состояния синтетической фотонной решетки, соответствующего заданному унитарному линейному преобразованию над входной последовательностью оптических импульсов. Как и следовало ожидать, обучение происходило тем быстрее, чем больше отношение числа слоев М (т.е. числа обходов синтетической фотонной решетки) к размеру $\mathrm{N}$ воспроизводимой унитарной матрицы.

Таким образом, мы продемонстрировали, что синтетическая фотонная решетка может играть роль оптической нейронной сети и реализовывать заданные линейные преобразования над временными последовательностями импульсов.

Работа выполнена в рамках государственного задания FSUS-2020-0034.

\section{Литература}

[1] Shen, Yichen, et al. Nature Photonics 11, 441 (2017).

[2] Lin, Xing, et al. Science 361, 1004 (2018).

[3] Schreiber, A., et al. Physical review letters 106, 180403 (2011).

[4] Wimmer, Martin, et al. Nature Physics 9, 780 (2013).

[5] Regensburger, Alois, et al. Physical Review Letters 110, 223902 (2013).

[6] A. Pankov et al. Sci. Rep. 9, 3464 (2019).

[7] Weidemann, Sebastian et al. Science 368, 311 (2020). 